\title{
LA ESCRITURA PIANISTICA DE MANUEL MARÍA PÁRRAGA
}

Jesús Andrés Roa Zúñiga ${ }^{12}$

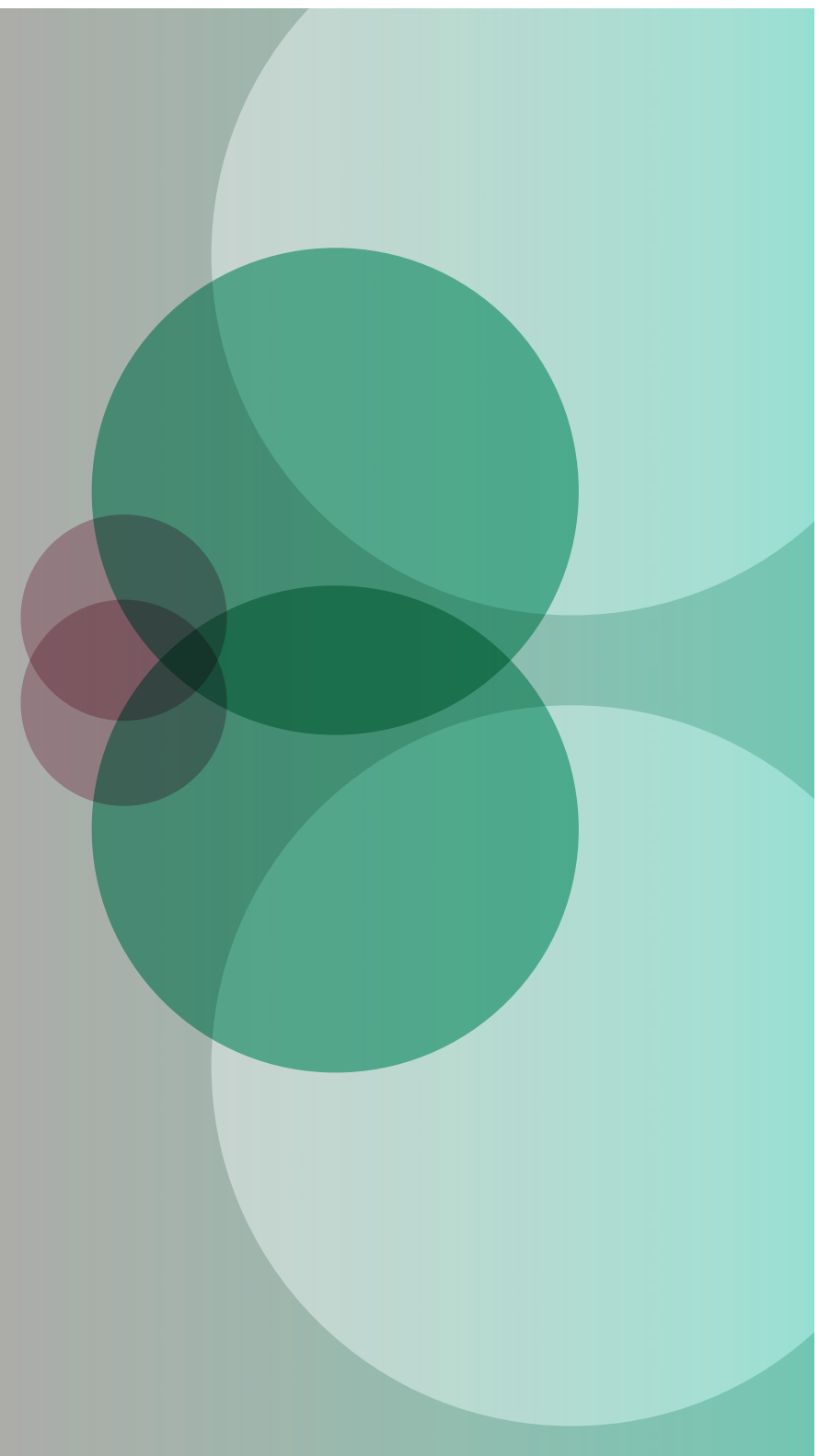

12 Pianista egresado de la Universidad del Cauca; estudiante de Maestría en Interpretación de la Universidad EAFIT, andresroa3000@yahoo.com

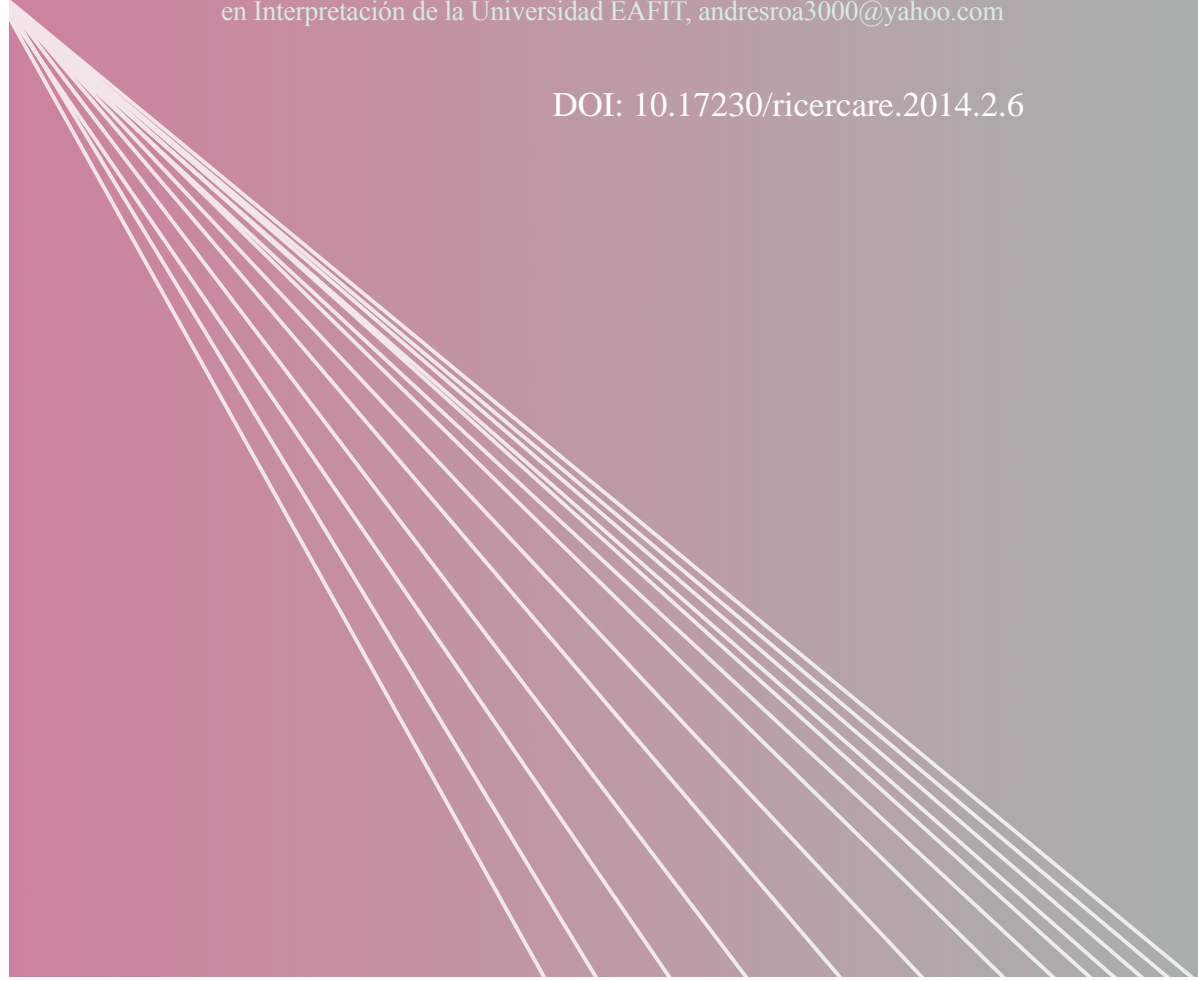




\section{Resumen}

La figura de Manuel María Párraga Paredes permanece rodeada de misterio pese a su importancia para la literatura pianística nacional, este trabajo pretende resaltar la calidad de la obra de dicho compositor y su aporte al repertorio colombiano para piano del siglo XIX.

A partir del análisis de la escritura pianística, la forma, la armonía y otras particularidades de la obra de Párraga, y haciendo una aproximación a la biografía y al contexto socio-político del autor en la época Neogranadina, esta edición crítica y revisada de (cuatro) de sus obras para piano, busca despertar el interés de las nuevas generaciones de músicos en la obra pianística de Párraga Paredes.

\section{Summary}

The figure of Manuel María Párraga is surrounded by mystery, regardless of his importance for the national piano literature. This article intends to highlight the quality of this composer's works and his contribution to the Colombian piano repertoire of the 19 th century.

This revised and commented edition of four of Párraga's piano works intends to attract the interest of new generations of musicians to the works of the composer, through the analysis of piano writing, form, harmony, and other details; as well as by commenting on the sociopolitical context surrounding the Neo-Grenadine period when the pianist lived. 


\section{INTRODUCCIÓN}

La figura de Manuel María Párraga permanece rodeada de misterio, pese a su importancia para la literatura pianística nacional. Se desconoce mucho acerca de su vida, puesto que no se tiene la certeza de que haya nacido en Colombia; incluso, es citado como venezolano por Andrés Pardo Tovar (1966) y su producción pianística se ha difundido muy poco, con excepción de algunas obras suyas ampliamente popularizadas, que son: El bambuco, aires nacionales neogranadinos op. 14, El tiple, torbellino, y El valse, publicado por Duque Hyman (1998). Como se enunció, es un compositor casi olvidado en el campo académico en el país.

Mediante este artículo pretendo analizar a grandes rasgos la producción y la escritura pianística de Párraga, sus influencias, sus texturas armónicas y su organización formal, con el objetivo de lograr una mejor comprensión de la obra para piano de dicho autor, teniendo en cuenta el contexto histórico, social y político de la época en la que desarrolló su obra.

Se estima que Manuel María Párraga vivió entre 1826 y 1895 y que su maestro fue el músico venezolano Nicolás Quevedo Rachadell; se sabe que estudió y residió en Europa, lo cual es evidente en su escritura pianística; incluso, se rumora que estudió o que, al menos, tuvo algún tipo de contacto con Liszt. Las obras que se encuentran en la sala de patrimonio documental de la Universidad EAFIT fueron editadas en su totalidad por la reconocida editorial Breikopft \& Hartel. En Colombia, su actividad como compositor también fue complementada con la de pianista en la orquesta de la Sociedad de Conciertos que en 1846 fundara don Enrique Price; en 1857, tras la desaparición de dicha sociedad, Párraga centró su actividad en la Unión Musical, creada por él, en asociación con el violinista alemán Alejandro Linding.

La vida de Manuel María Párraga se enmarca el siglo XIX, una época de grandes cambios sociales y políticos, caracterizados por la inestabilidad de una república que había obtenido su independencia en época reciente y, por tanto, en formación, llena de herencias euro- peas, africanas e indígenas, pero que no se reflejaban en muchos ámbitos de la vida nacional, en la cual se empezaba a buscar una identidad propia y a construir su presente y futuro. Fue, entonces, cuando todo el movimiento romántico europeo se volcó sobre nosotros con gran fuerza en todas sus expresiones: pintura, escultura, narrativa, poesía, ensayo y, por supuesto, música, fue entonces cuando nuestro panorama artístico se vio enriquecido con la llegada de compañías de ópera, teatro y solistas varios, que poco a poco empezaban a incluir en sus giras de conciertos a las recién nacidas repúblicas suramericanas. No es de extrañar que nuestros compositores fueran influenciados en alto grado por todas estas corrientes externas y que empezaran a hacer brillantes creaciones musicales en el estilo romántico de la época, haciendo gala de todos los recursos aportados por él.

El Romanticismo europeo se desarrolló durante casi todo el siglo XIX y, al igual que en Latinoamérica, estuvo marcado por múltiples emancipaciones y movimientos revolucionarios; los ideales de la Revolución Francesa fueron determinantes en su desarrollo: la exaltación de la libertad del hombre, de sus ideas y emociones fue el germen de la ruptura con los moldes tradicionales y la formación de un estilo por completo diferente, en el que la equilibrada racionalidad de los clásicos es abandonada poco a poco y más tarde de manera total, para dar rienda suelta al río desbocado de los sentimientos del hombre, de sus ideas, de sus emociones. Va quedando atrás el prototipo de artista al servicio de la corte, que escribe para las necesidades de la misma, para dar paso al genio creador libre, con la capacidad de escoger sus propios temas de inspiración, entre los cuales figurarán, de manera especial, el amor, la exaltación patriótica, la muerte, la lucha del hombre contra su destino y las leyendas antiguas, que tomarán, incluso, un tinte programático musical.

El intercambio cultural entre América y Europa fue de suma importancia en la consolidación de las artes en nuestro continente, más aún en el contexto histórico que nos atañe: el siglo XIX; el romanticismo, en todas sus expresiones, se propagó con una rapidez vertigi- 
nosa y arrolladora y su influencia se extendió más allá de las fronteras del viejo continente; nuestro momento histórico no podía ser más propicio para que esta influencia fuera ejercida en forma contundente, puesto que las recién constituidas repúblicas, y sus sociedades emergentes reclamaban acusadamente la búsqueda de la identidad nacional, en los valores sociales, en lo político, en lo artístico, lo cual encajaba con los ideales románticos y generaba un caldo de cultivo óptimo para que los últimos se volvieran con rapidez parte de nuestro medio.

Desde el punto de vista educativo y, de modo más específico, en lo que a la educación musical se refiere, Europa fue fundamental en la formación de los jóvenes compositores e intérpretes latinoamericanos, pues se nutrieron del sistema educativo europeo, ya fuera estudiando en las instituciones nacionales que en forma nítida copiaban sus modelos, aprendiendo de los artistas que llegaban como producto de las giras de conciertos, o simplemente viajando a estudiar en forma directa al viejo continente para volver después, por lo general con un criterio formado integralmente, que se mezclaría con la identidad propia para dar, como resultado, artistas que, en su obra supieron combinar todos los elementos mencionados para crear arte nacional de primer nivel. Fue el caso de Párraga, de quien, si bien no estamos seguros de que haya nacido en nuestro territorio, sin duda aportó a nuestro desarrollo musical, desde las perspectivas de la interpretación, la composición y la difusión musical, con su trabajo en la Sociedad de Conciertos y con posterioridad en la Unión Musical. El piano se impuso con gran fuerza durante este período; algunos lo consideran de manera categórica, y no con poca razón, el instrumento rey del Romanticismo, el canal de comunicación por excelencia de los compositores de la época; no es casual que desde Beethoven hasta Tchaikovsky, pasando por Liszt, Chopin, Schumann, Mendelssohn, Grieg, Tausig, Thalberg y Alkan, entre muchos otros autores mayores y menores, se hayan dedicado infinidad de páginas a este instrumento y que figuren muchas de estas como obras fundamentales dentro del desarrollo estético y estilístico de la música del siglo XIX en Europa.
El desarrollo mecánico del instrumento también avanzó a un ritmo vertiginoso desde 1800 hasta nuestros días, ya que cada vez la imaginación sonora de los compositores y las peripecias técnicas de los pianistas virtuosos demandaban instrumentos de mayor calidad, en lo referente a sonoridad, mecanismo de repetición e, incluso, en cuanto a resistencia del instrumento, ya que los frágiles instrumentos que aparecieron en las primeras épocas con dificultad hubieran soportado las exigencias de fuerza inherentes a las obras que se estaban escribiendo para el piano. Esta evolución dio paso a un universo de sonoridades nunca antes visto, $\mathrm{y}$ favoreció la fascinación de los compositores por la exploración tímbrica; como ejemplos de este fenómeno podemos citar el comienzo de la Polonesa Fantasía, de Chopin, y Les jeux d'eau à la villa d'Este, de Liszt, obras en las que la sonoridad se torna "casi impresionista" y en las cuales, sin duda, se abre el camino a invenciones posteriores de brillante sonoridad como Jeux d'eau, de Ravel, en la que la respuesta tímbrica del instrumento juega con claridad un papel preponderante.

\section{La pieza de carácter en el siglo XIX y en la producción de Manuel María Párraga}

El término se deriva del alemán Charakterstück y está ligado en forma directa, desde sus orígenes, a la música escrita para piano, aunque se encuentran también diversos ejemplos de este tipo de piezas en el repertorio de otros instrumentos. Aunque la definición del término carece de precisión, en lo primordial la pieza característica hace referencia a música que se basa en un programa dado o en una idea, muchas veces, en esencia, simple, que busca evocar una emoción o un momento particular.

Los románticos cultivaron con especial dedicación la pieza de carácter; en la producción de Schumann, Schubert, Chopin, Brahms y Liszt encontramos ejemplos numerosos; Schumann, en las Piezas fantásticas op. 12, nos muestra una clara ilustración de este género en pequeños trozos de corta extensión, con títulos tan sugestivos como ¿Por qué?, Pesadillas y En el atardecer; también en la Kreisleriana op. 16, pese a su larga duración, pue- 
de considerarse una gran pieza de carácter en la que se suceden las emociones, sentimientos y estados anímicos del Kappelmeister Kreisler de forma contrastante; Schubert, por su parte, nos ofrece piezas características en sus Impromptus, Momentos musicales, lo mismo que Chopin en sus Preludios, Polonesas, algunos de sus Estudios y en movimientos de sus Sonatas, como en los movimientos tercero y cuarto de la op. 35: la inolvidable Marcha fúnebre, y el presto que la sucede, que ha sido considerado como más trágico, aún, al evocar el viento sobre las tumbas en la noche, pasado ya el cortejo mortuorio. En Liszt abundan las obras de corte característico y programático; encontramos ejemplos importantes en sus Doce estudios de ejecución trascendental, como Mazeppa y Feux follets, y otras tantas, como Sueño de amor, Vals Mephisto, Funerales, la bendición de Dios en la soledad (basada en un poema de Alphonse de Lamartine), entre muchas otras. Liszt traspasó los límites de la pieza de carácter y del piano en sus Poemas sinfónicos, creando un género de gran trascendencia y que influiría en forma notoria en muchos de los compositores de la centuria y posteriores. La pieza de carácter también fue cultivada de manera extensa en el siglo XIX por compositores considerados menores pero que eran grandes virtuosos del teclado, que alcanzaron una popularidad enorme en su época, popularidad que, en muchos casos, no perduró y produjo el olvido de este repertorio hasta el siglo XX, en el que la difusión del disco y el internet han provocado el redescubrimiento de muchas páginas de música, llenas de enormes dificultades técnicas y de considerable contenido musical en ocasiones. Los nombres de Charles-Valentin Alkan, Sigismund Thalberg y Daniel Steilbelt, entre otros, merecen ser destacados, como también muchas de sus obras: Doce estudios en los tonos menores, Sinfonía para piano solo, Concierto para piano solo, Sonata las cuatro edades, Estudio de concierto Le Preux, entre las obras de Alkan, y las fantasías de ópera sobre Robert le diable de Meyerbeer, Norma de Bellini, op. 2, entre muchas otras composiciones de Thalberg.

En la producción para piano de Manuel María Párraga que ha llegado hasta nosotros se encuentran, en lo primordial, piezas de carácter, con todas las características propias de aquellas escritas por sus contemporá- neos europeos: títulos sugestivos, llamativos y casi "coloridos", en ocasiones alusivos a sucesos y personajes de la época, como también a emociones y sentimientos; uso predominante de una forma ternaria sencilla, y de aires que eran populares en ese entonces, por lo general heredados de la tradición europea, como polkas, valses, mazurcas y otros más autóctonos, como el torbellino y el bambuco; escritura pianística de suficiente complejidad y uso de todos los recursos técnicos aplicables al teclado: pasajes de dobles notas en terceras, sextas y octavas simples y dobles, pasajes de escalas $\mathrm{y}$ arpegios en combinaciones y mixturas enriquecidos con el manejo apropiado de una armonía típicamente romántica y decimonónica, dentro de un contexto tonal tradicional, pero siempre ingenioso, y al servicio de la descripción de sus títulos y de un efectismo propio de la música de salón tan popular en la Europa de la época, que fue importada a nuestra América Latina y que se arraigó con celeridad en nuestra sociedad del siglo XIX. Citemos pues las piezas de carácter de Párraga que reposan en la colección de partituras de la Universidad EAFIT; de estas extractaré unas pocas para realizar los comentarios correspondientes.

- Los candidatos (polkas)

- Sultana (gran nocturno de concierto)

- El tiple (torbellino)

- Le ruisseau (valse brillante)

- Sofía (polka brillante)

- Minerva (valse brillante)

- La novia (polka-mazourka)

- Edda (polka brillante)

- Virginia (polka brillante)

- Matilde (polka-mazourka)

- La solitude (morceau de salón)

- Inés (polka-mazourka)

- El bambuco, op. 14 (aires nacionales neogranadinos)

\section{Le ruisseau - Valse brillante}

Se trata de una pieza de carácter brillante, virtuoso y ágil, escrita en la tonalidad de mi bemol mayor, dedicada a la señorita Matilde Urdaneta, y cuya estructura podría resumirse de la siguiente manera: introducciónA-A'-A-coda. 
Comienza con una introducción, Andante capriccioso (compases 1 a 18), que alterna escalas al unísono en ambas manos en matices ff $\mathrm{y} f$, con figuraciones de semicorcheas en la derecha, en matices $p p$ y $p$, que, a su vez, constituyen insinuaciones del material temático que el compositor usará en la primera sección del vals; después de una serie de acordes que, en últimas, reposan sobre la dominante, se da paso a la primera sección de esta pieza escrita en binaria compuesta.

Sección A (compases 19 a 66):

Consta de dos partes principales que se suceden de la forma siguiente: una primera idea, que consta de un período (compases 19 a 26), con su variación en los siguientes ocho compases: (compases 27 a 34), y otra idea (compases 35 a 50), que está formada por un período (compases 35 a 42) y su repetición idéntica (compases 43 a 50); la primera parte de A está elaborada con el desarrollo de las figuraciones de semicorcheas en la mano derecha que se habían insinuado en la introducción, cuya indicación dinámica es $p$ leggierisimo, y no son más que bordados sobre las notas pilares de las tríadas fundamentales y la tonalidad axial (mi bemol mayor) y cercanas, alternadas con escalas que generan un efecto de Jeu perlé muy efectista y característico de la escritura de la época, y que, debido a su textura y a su construcción rítmica, contrastan con la segunda idea de A, en la que Párraga reemplaza los grupos ininterrumpidos de semicorcheas por tresillos que se responden entre las manos a manera de diálogo; esta figuración está elaborada todo el tiempo con dobles notas, y aquí el autor juega de forma magistral con la alternancia de sextas, terceras y octavas, sin apartarse de la tonalidad principal.

Después de recapitular la primera idea de A, de manera idéntica aparece la sección central del vals, que llamaré A' (compases 67 a 102), en la tonalidad de la bemol mayor, marcada por Párraga como Meno mosso, cantabile, en la cual se aprecian dos subsecciones principales (compases 67 a 82 y 83 a 102); la primera de ellas está formada por un período (compases 67 a 74) y la varia- ción del mismo (compases 75 a 82) y nos presenta una sencilla melodía en matiz $p$, que se contrapone a una gruesa textura de acompañamiento armónico en ambas manos que aparece de manera simultánea, lo que genera una densificación del fragmento; pese a esto, la pureza y la fluidez de la línea melódica no debe en ningún momento verse afectada, lo cual plantea un reto interpretativo claro: el control de los planos sonoros en función de la fluidez de la melodía. Por el contrario, en la segunda idea de A', Párraga retorna a una textura más esbelta, en la que la melodía, con molta espressione, tiene un sencillo acompañamiento de vals, muy acertado, pues permite que los pasajes de escalas y arpegios, que también aparecen en esta sección, resulten brillantes sin mayor esfuerzo, debido a la interacción equilibrada entre acompañamiento y melodía.

Después de un pequeño puente (compases 98 a 102), construido a partir de acordes arpegiados simultáneos en $p p$, y que reposa sobre la dominante de mi bemol mayor, se da paso a la recapitulación completa de la sección A y con posterioridad a la coda (compases 151 a 166), marcada con la indicación più mosso, cuya estructura rítmica, en tresillos de corcheas y negras, parece recordar la coda del impromptu en mi bemol, op. 90, número 2, de Franz Schubert, casualmente escrito en la misma tonalidad. La pieza concluye en forma brillante con escalas en movimiento contrario, simples y en octavas, rematadas por cuatro acordes secos.

\section{Sultana-Grand nocturne de concert}

Este Grand nocturne de concert es justamente eso, una pieza concertante, al mejor estilo de las fantasías brillantes para de piano de autores del siglo XIX, como Liszt, Tausig, o Alkan, y está dedicada al señor Raimundo Santamaría, su estructura formal -un poco más extensa y elaborada que Le ruisseau- se aprecia con claridad en el siguiente esquema: introducción-A-B-A(repetición variada)-B-coda-sección conclusiva.

La introducción, marcada Allegro con fuoco-agitato, consta de dos secciones principales; la primera (compases 1 a 15) nos deja en forma nítida, a través de su tipo de escri- 
tura, que se está frente a una pieza de bravura, que emplea con abundancia trémolos y octavas; la segunda sección de la introducción (compases 16 a 34) comienza con la indicación dolente (compases 16 a 23), acentúa ese pequeño momento de lirismo que contrastará con las repeticiones insistentes de acordes con las que continúa la introducción (compases 24 a 34), muy similares a las que encontramos en muchos de los agitato de la Fantasia quasi sonata, Après une lecture de Dante, de Franz Liszt.

La sección A, con grande espressione, dolcissimo (compases 35 a 63) nos presenta una melodía de gran lirismo en la mano derecha, acompañada en tresillos por la izquierda; esta sección gira en torno a la tonalidad de mi bemol menor y termina en la misma, para ser interrumpida con brusquedad por la sección B (compases 64 a 95), que irrumpe de forma súbita sobre la tonalidad mayor directa (mi bemol mayor) con tutta forza, cuya indicación dinámica marcada es fff; toda la sección está elaborada con acordes repetidos en semicorcheas en la mano derecha que, por momentos, doblan la melodía, que aparece en el extremo superior de los acordes que toca la izquierda, y que contrastan en forma amplia con el carácter tranquilo y melódico de la sección A; en esencia, en esta parte, que he llamado B, hay dos frases en mi bemol mayor (compases 64 a 71 y 79 a 86), y que se repiten de manera exacta (compases 72 a 78 y 87 a 95), en un rango dinámico bastante amplio, que abarca desde el $p p p$ hasta el fff.

La repetición variada de A ( $p$ leggierissimo), en la que se retorna a mi bemol menor, está elaborada a partir de pasajes de arpegios e intervalos quebrados, que dejan entrever los rasgos y las notas de la melodía que aparecía originalmente en la primera versión de A; después de terminar en forma tranquila, es de nuevo interrumpida por la sección B en fff pesante (compases 125 a 140), con un tratamiento similar en cuanto a textura, pero esta vez recortada, dado que en este caso se omitieron las repeticiones literales de las dos frases principales que forman la sección.

La coda, più mosso (compases 141 a 194), se divide en dos subsecciones principales: la coda propiamente dicha (compases 141 a 176) y la sección conclusiva (compases
177 a 194). La primera parte de la coda está repleta de octavas quebradas de bravura en la mano derecha, lo cual, sin duda, es exigente desde el punto de vista técnico, dado que el ejecutante debe incrementar la velocidad de la pieza y mantener ese incremento de tempo, sobreponiéndose a la fatiga que implica este tipo de pasajes; el reto se vuelve aún mayor en la sección conclusiva, con la indicación $i l$ piú presto possibile, y el engrosamiento de la textura, con la aparición de pasajes de acordes quebrados y octavas en simultaneidad, que nos recuerdan algunos giros armónicos que aparecieron en el cuerpo de la obra; estas complejas figuraciones pianísticas plantean una dificultad considerable, debido, sobre todo, a la insistencia del matiz ff hasta el final de la pieza, que termina con vigorosos acordes de mi bemol mayor que recorren buena parte de la extensión del teclado, para concluir sobre el registro medio del instrumento.

\section{La solitude - Morceau de salón, op. 4}

A La solitude la denomina el autor Morceau de salón; sin embargo, además de una pieza de salón, es una fantasía de concierto, debido a la libertad casi rapsódica con la que plantea sus temas, las variantes de los mismos y la interrelación entre sus secciones.

Está dedicada a su amigo, el señor Manuel Umaña, y su estructura puede plantearse de la manera siguiente: introducción-A-A(variada)-B-B(variada)-C-coda.

En la introducción (compases 1 a 38) se encuentra la indicación Maestoso, risoluto, en matiz $f$ y en ella pueden apreciarse dos partes principales (compases 1 a 12 y 13-38). La primera nos recuerda las introducciones de las muchas fantasías y paráfrasis de óperas, escritas por los compositores-pianistas del siglo XIX; aquí, Párraga usa acordes quebrados repartidos entre las dos manos, que giran en torno a los grados principales de la tonalidad, y alternan entre los registros grave y agudo del instrumento, lo que genera un efecto de contraste, de tipo claro-oscuro, para dar paso a la segunda parte de la introducción: $p$ poco piú lento, dolente, en la que predomina la utilización de notas repetidas, primero entrecortadas por silencios y después alternadas con 
octavas quebradas, todo lo cual forma una línea ininterrumpida hasta el final de la sección introductoria; en este punto, la textura se torna mucho más clara, debido a una mayor separación del registro entre las manos y a la utilización del sector agudo del mismo; por último, y después de descansar sobre la dominante con séptima (compases 37 y 38) aparece la idea A.

La misma está planteada como una tranquila melodía en tempo de Adagio, acompañada por arpegios en semicorcheas de la mano izquierda (compases 39 a 46), es un típico período de ocho compases, que se repite a continuación, mediante la versión en octavas de la melodía en la mano derecha (compases 46 a 54); en seguida aparece una idea subordinada, con dolore (compases 54 a 58) que, después de alternar con el consecuente de la melodía principal, da paso a la repetición de la sección; en este caso, la repetición es una variación de la misma; en ella, Párraga se sirve de veloces figuraciones arpegiadas y escalísticas para su desarrollo; tras brillantes cadencias en filigrana (compases 85 a 86) termina la variación, cuyo tipo de escritura bien podría recordar las variaciones VII y XVIII del gran estudio sobre los tonos menores op. 39, número 12, Le festin d'Esope, de Charles-Valentin Alkan.

A continuación, la sección B, en compás de 4/4, está basada en dos períodos (compases 88 a 95 y 104 a 111), con su correspondiente repetición (compases 96 a 103 y 112 a 120), de forma casi idéntica, salvo por la reiteración a la octava del primer período (compases 93 a 103). La variación que sigue conserva la estructura de B, pero en este caso el $4 / 4$ se transforma en tempo de valse.

Después de una pequeña sección, C, que está formada por un período, y la correspondiente variación del mismo, en una simétrica estructura de 16 compases con su correspondiente repetición, se encuentra la coda, vivo, sempre ff, que está elaborada con escalas brillantes de sol mayor y que termina con una serie de acordes secos, realzados con la indicación $s f$.

\section{El bambuco - Aires}

nacionales neogranadinos, op. 14

Se trata, sin duda, de una de las obras más divulgadas y conocidas de Párraga, que se ha incorporado al repertorio de concierto, debido a su singular equilibrio entre virtuosismo y presentación de aires autóctonos de fácil asimilación por parte del oyente.

Su estructura, de predominante binariedad, presenta dos secciones principales, que alternan con sus repeticiones ornamentadas, con una pequeña introducción y una breve coda.

Esquema ilustrativo: introducción-A-A'-A (variado)A'(variado)-coda.

La introducción (compases 1 a 11) alterna furiosas escalas en octavas y arpegios disminuidos, ff ad libitum, en el registro grave del instrumento, con ornamentos $p p$ en el sector agudo del mismo; después de dos compases en rallentando encontramos la sección A (compases 12 a 118), allegro capriccioso, en la tonalidad de sol sostenido menor, que, luego de cuatro compases rítmicos, que evocan el acompañamiento rítmico típico de la tambora en el bambuco, nos presenta un serie de melodías que se suceden sin interrupción, usando todo el registro medio-agudo del instrumento, y que, sin duda alguna, están muy de acuerdo con el título: aires nacionales neogranadinos, ya que evocan con claridad los giros armónicos y melódicos de la música de la época; esta sección es bastante extensa (107 compases) e implementa, desde su comienzo, el acompañamiento rítmico de bambuco, que va a prevalecer durante toda la obra.

En seguida encontramos la sección A'(compases 119 a 163), escrita en la tonalidad de la bemol mayor, en la que dos melodías del mismo tipo que las de la sección A se alternan entre sí, variando su modalidad y el registro de su escritura; hablo puntualmente de los siguientes grupos de compases: 123 a 138 y 138 a 146, y la respectiva reiteración del primer grupo (compases 147 a 154); después de un pequeño puente en el que de manera momentánea se rompe el ostinato rítmico 
del acompañamiento, se retoma la sección A, y vuelve el acompañamiento de bambuco.

La nueva aparición de las secciones A y A' (compases 164 a 198 y 199 a 231) está elaborada a partir de variaciones virtuosísticas sobre los motivos presentados con anterioridad; pasajes de tresillos de semicorcheas, que conservan rasgos armónicos y melódicos de los motivos mencionados, desembocan en una pequeña, pero poderosa coda (compases 232 a 243), escrita en octavas $\mathrm{y}$ arpegios quebrados, que finaliza $f f$ en la bemol mayor.

\section{CONCLUSIONES}

El aporte de Manuel María Párraga a la literatura colombiana para piano es relevante; pese a la excelente calidad de su escritura y a la riqueza de sus melodías, su obra -con contadas excepciones- ha permanecido en el olvido, y fuera del repertorio pianístico colombiano que se ejecuta hoy en día en conciertos. Con seguridad, Párraga fue un pianista de gran vuelo, y considero que su obra debe difundirse e implementarse en la formación de los jóvenes pianistas, ya que, debido a su factura instrumental, sin duda aportará interesantes elementos técnicos e interpretativos, de común utilización en el repertorio tradicional del piano.

Durante mucho tiempo se ha acusado al repertorio colombiano para piano de "no tener suficiente desarrollo pianístico", afirmación errada e injusta, pero difundida. Compositores como Manuel María Párraga, entre otros tantos, generan razones suficientes para rebatir dicha afirmación y regresar la mirada a nuestro repertorio nacional.

\section{REFERENCIAS}

Béhague, G. (1983). La música en América Latina. Caracas: Monte Ávila.

Bermúdez Cújar, E. (1984). Nacionalismo y cultura Popular. El nacionalismo en el arte. Bogotá: Universidad Nacional de Colombia, Instituto de Investigaciones Estéticas, Facultad de Artes, Centro Hábitat de Colombia.

Bermúdez Cújar, E. (1985). Historia de la música vs historias de los músicos. Revista Universidad $\mathrm{Na-}$ cional de Colombia, Bogotá, I(3), 5-17.

Bermúdez Cújar, E. (1984). La música en el arte colonial de Colombia. Bogotá: Fundación de Mvsica.

Bermúdez Cújar, E. (1996). La música campesina y popular en Colombia, 1880 - 1930. Gaceta, Colcultura, Bogotá, 32-33, 13-20.

Bermúdez Cújar, E. (1999). Un siglo de música en Colombia. ¿Entre nacionalismo y universalismo? Credencial Historia, Bogotá, 120, 8-10.

Bermúdez Cújar, E. (2000). Historia de la música en Santa Fe y Bogotá. 1538 - 1938. Bogotá: Fundación de Mvsica.

Bermúdez Cújar, E., ed. (2001). Musicología en Colombia. Historia y Teoría del Arte y la Arquitectura. Bogotá: Universidad Nacional de Colombia.

Duque Hyman, E. A. (1984). Paradigma de lo nacional en la música. El nacionalismo en el arte. Bogotá: Universidad Nacional de Colombia, Instituto de Investigaciones Estéticas, Facultad de Artes, Centro Hábitat de Colombia.

Duque Hyman, E. A. (1993). La cultura musical en Colombia, siglos XIX y XX. Gran enciclopedia de Colombia, vol. 6. Bogotá Círculo de Lectores.

Duque Hyman, E. A. (1998). La música en las publicaciones periódicas colombianas del siglo XIX: 18481860, 2 vols. Bogotá: Fundación de Mvsica.

Pardo Tovar, A. (1943). El arte vernáculo, folclore colombiano. Micro, Bogotá, ..., 18-19. 
Pardo Tovar, A. (1966). La cultura musical en Colombia. Vol. XX, en Historia Extensa de Colombia, vol. XX, tomo 6. Bogotá: Academia Colombiana de la Historia / Ediciones Lerner, 1966.

Perdomo Escobar, J. I. (1980). Historia de la música en Colombia, $5^{\underline{a}}$ ed. Bogotá: Plaza y Janés.

Rodríguez Álvarez, L. C. (2007). Músicas para una región y una ciudad: Antioquia y Medellín. 1810-1865. Aproximación a algunos momentos y personajes. Medellín: Instituto para la el Desarrollo de Antioquia (IDEA).
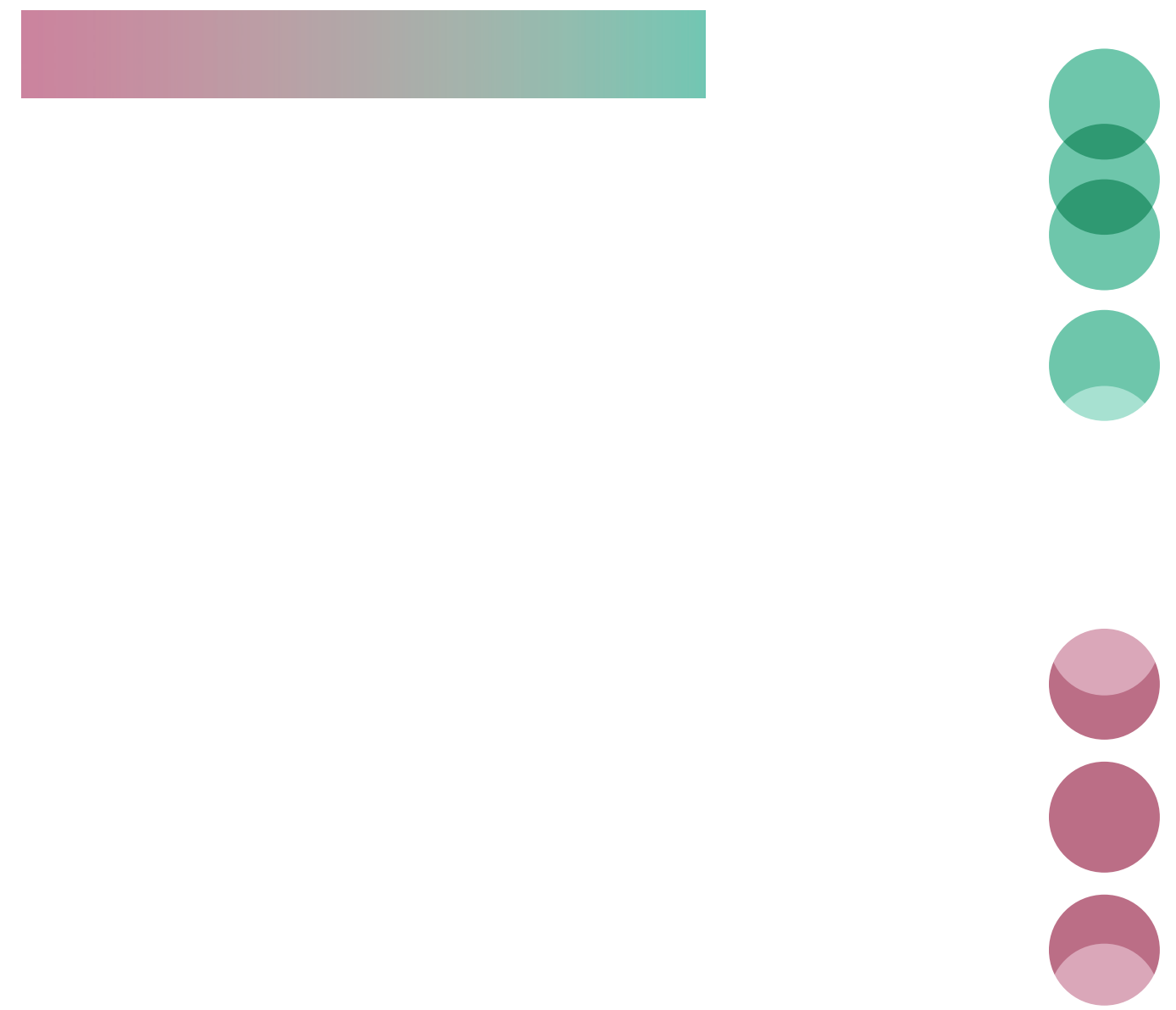